\title{
Preface
}

\section{Lynch syndrome (HNPCC) and microsatellite instability}

\author{
Asad Umar \\ Gastrointestinal and Other Cancers Research Group, Division of Cancer Prevention, National Cancer Institute, \\ EPN, Suite 2141, 6130 Executive Boulevard, Bethesda, MD 20892-7317, USA \\ Tel.: +1 301594 2684; Fax: +13014356344
}

\begin{abstract}
A departure from the concept of simple adenoma to carcinoma sequence is the realization that colorectal cancer (CRC) develops through at least two major molecular pathogenic pathways, namely chromosomal instability (CIN) and microsatellite instability (MSI) $[1,2]$. The mechanisms underlying CIN might have been the first to be deciphered but they are just being understood in detail. It is proposed that CIN may be associated with defects in mitotic spindle apparatus hence tumors arising through this pathway are usually characterized by widespread chromosomal deletions, translocations and loss of heterozygosity at the molecular level. On the other hand, MSI pathway is responsible for up to $15 \%$ of all CRCs that also include a number of familial syndromes $[3,4]$. Hereditary non-polyposis colorectal cancer (HNPCC also known as Lynch syndrome) is the prototype for the tumors characterized by MSI. Tumors developing through this pathway have alterations in the length of short, repeated (usully mononucleotide or dinucleotide) sequences of DNA, i.e., microsatellites [5-10]. This phenomenon reflects the underlying defect in the DNA mismatch repair (MMR) system which is a multi-protein complex responsible for correction of errors arising during normal cell division $[5,7,11,12]$.
\end{abstract}

In 1997, the National Cancer Institute Workshop on Hereditary Non-polyposis Colorectal Cancer Syndrome proposed specific markers for MSI assessment which included BAT25, BAT26, D5S346, D2S123 and D17S250, known as Bethesda panel [13]. If no alter- ations are found the tumor is classified as microsatellite stable (MSS) and if two or more loci are abnormal the tumor is classified as showing a high level of microsatellite instability (MSI-H). In cases showing abnormalities at one locus, testing of an additional five loci is recommended. If abnormal loci constitute less than $40 \%$ of the tested markers, the tumor is classified as showing a low level of microsatellite instability (MSIL). MSS cancers account for up to $85 \%$ of all CRCs and occur in sporadic and hereditary settings such as familial adenomatous polyposis (FAP) and attenuated FAP. The biological significance and underlying genetic abnormalities in cancers with the MSI-L phenotype are debated and remain to be fully characterised. It has been reported that on morphological grounds, MSS and MSI-L cancers are indistinguishable. MSI-H cancers constitute up to $15 \%$ of all CRCs. MSI-H cancers (sporadic and in hereditary non-polyposis colorectal cancer (HNPCC) patients) have characteristic anatomical and histological features. Proximal colon incidence is seen in the majority of cases. Most of the tumors are polypoid masses and some may display a mucinous cut surface $[14,15]$. Stricture formation due to a diffuse growth pattern is uncommon; however, extensive necrosis is often observed. The tumors usually have a well-defined margin. A significant fraction of tumors are also classified as poorly differentiated. A characteristic feature of diagnostic importance is the presence of tumor infiltrating lymphocytes (TIL), most of which are cytotoxic T cells. B lymphocytes' aggregates are 
seen deep in the tumor, and sometimes referred as a Crohn's-like reaction especially in the cases with MSI$\mathrm{H}$ phenotype [16]. Somatic genetic alterations accumulated during tumor progression include mutations in short repeat sequences within the coding regions of TGFRII, IGFIIR, and BAX, the genes which play an important role in both cell growth and survival. ( [17] and reviewed in [18]).

Since experimental studies with MSI-positive and negative cell lines as well as clinical data suggest different responses to chemotherapeutic agents, the assessment of MSI status of the tumors is important. It also serves as a screening method for tumors of the HNPCC spectrum. In cases of sporadic colorectal cancer there is a growing body of evidence indicating the improved prognosis associated with this group of tumors. Furthermore, failure to recognize familial cancer will have a negative impact on the patient's and family's management. Molecular testing for MSI is relatively expensive, however, a combination with immunohistochemical (IHC) detection of mismatch repair defects provides some relief to the cost as IHC is relatively inexpensive, fast and technically simple.

Based on the SEER data and the MSI CRC incidence approximately 22,000 cases of MSI cancers were recorded for 2003 in the US and 75,000 cases Worldwide. Despite that until recently, there was no accepted recommendation indicating the number, type, and identity of microsatellites which should be used for MSI testing. This special issue of Disease Markers is focused on both the disease manifestations as well as the recent revised Bethesda Guidelines $[18,19]$ for the diagnosis and decision for genetic testing that will eventually lead to better understanding of the Lynch syndrome (HNPCC) and the MSI phenotype.

\section{References}

[1] E.R. Fearon and C.V. Dang, Cancer genetics: tumor suppressor meets oncogene, Curr Biol 9(2) (1999), R62-65.

[2] E.R. Fearon, Human cancer syndromes: clues to the origin and nature of cancer, Science 278(5340) (1997), 1043-1050.

[3] H.T. Lynch and A. de la Chapelle, Genetic susceptibility to non-polyposis colorectal cancer, J Med Genet 36(11) (1999), 801-818.

[4] H.T. Lynch and K. Kaul, Microsatellite instability, clinical implications, and new methodologies, J Natl Cancer Inst 92(7) (2000), 511-512.

[5] A. Umar, J.C. Boyer, D.C. Thomas, D.C. Nguyen, J.I. Risinger, J. Boyd, Y. Ionov, M. Perucho and T.A. Kunkel, Defective mismatch repair in extracts of colorectal and endo metrial cancer cell lines exhibiting microsatellite instability, $J$ Biol Chem 269(20) (1994), 14367-14370.

[6] M. Perucho, Cancer of the microsatellite mutator phenotype, Biol Chem 377(11) (1996), 675-684.

[7] R. Parsons, G.M. Li, M.J. Longley, W.H. Fang, N. Papadopoulos, J. Jen, A. de la Chapelle, K.W. Kinzler, B. Vogelstein and P. Modrich, Hypermutability and mismatch repair deficiency in RER + tumor cells, Cell 75(6) (1993), 1227-1236.

[8] J.I. Risinger, A. Berchuck, M.F. Kohler, P. Watson, H.T. Lynch and J. Boyd, Genetic instability of microsatellites in endometrial carcinoma, Cancer Res 53(21) (1993), 5100-5103.

[9] L.A. Aaltonen, P. Peltomaki, J.P. Mecklin, H. Jarvinen, J.R. Jass, J.S. Green, H.T. Lynch, P. Watson, G. Tallqvist, M. Juhola et al., Replication errors in benign and malignant tumors from hereditary nonpolyposis colorectal cancer patients, Cancer Res 54(7) (1994), 1645-1648.

[10] L.A. Aaltonen, P. Peltomaki, F.S. Leach, P. Sistonen, L. Pylkkanen, J.P. Mecklin, H. Jarvinen, S.M. Powell, J. Jen, S.R. Hamilton et al., Clues to the pathogenesis of familial colorectal cancer, Science 260(5109) (1993), 812-816.

[11] J.G. Herman, A. Umar, K. Polyak, J.R. Graff, N. Ahuja, J.P. Issa, S. Markowitz, J.K. Willson, S.R. Hamilton, K.W. Kinzler, M.F. Kane, R.D. Kolodner, B. Vogelstein, T.A. Kunkel and S.B. Baylin, Incidence and functional consequences of hMLH1 promoter hypermethylation in colorectal carcinoma, Proc Natl Acad Sci USA 95(12) (1998), 6870-6875.

[12] A. Umar and T.A. Kunkel, DNA-replication fidelity, mismatch repair and genome instability in cancer cells, Eur J Biochem 238(2) (1996), 297-307.

[13] M.A. Rodriguez-Bigas, C.R. Boland, S.R. Hamilton, D.E. Henson, J.R. Jass, P.M. Khan, H. Lynch, M. Perucho, T. Smyrk, L. Sobin and S. Srivastava, A National Cancer Institute Workshop on Hereditary Nonpolyposis Colorectal Cancer Syndrome: meeting highlights and Bethesda guidelines, $J$ Natl Cancer Inst 89(23) (1997), 1758-1762.

[14] H.T. Lynch and P.M. Lynch, The cancer-family syndrome: a pragmatic basis for syndrome identification, Dis Colon Rectum 22(2) (1979), 106-110.

[15] H.T. Lynch, W. Kimberling, W.A. Albano, J.F. Lynch, K. Biscone, G.S. Schuelke, A.A. Sandberg, M. Lipkin, E.E. Deschner, Y.B. Mikol et al., Hereditary nonpolyposis colorectal cancer (Lynch syndromes I and II). I. Clinical description of resource, Cancer 56(4) (1985), 934-938.

[16] J.R. Jass, V.L. Whitehall, J. Young and B.A. Leggett, Emerging concepts in colorectal neoplasia, Gastroenterology 123(3) (2002), 862-876.

[17] R. Parsons, L.L. Myeroff, B. Liu, J.K. Willson, S.D. Markowitz, K.W. Kinzler and B. Vogelstein, Microsatellite instability and mutations of the transforming growth factor beta type II receptor gene in colorectal cancer, Cancer Res 55(23) (1995), 5548-5550.

[18] A. Umar, J.I. Risinger, E.T. Hawk and J.C. Barrett, Testing guidelines for hereditary non-polyposis colorectal cancer, Nat Rev Cancer 4(2) (2004), 153-158.

[19] A. Umar, C.R. Boland, J.P. Terdiman, S. Syngal, A. de la Chapelle, J. Ruschoff, R. Fishel, N.M. Lindor, L.J. Burgart, R. Hamelin, S.R. Hamilton, R.A. Hiatt, J. Jass, A. Lindblom, H.T. Lynch, P. Peltomaki, S.D. Ramsey, M.A. Rodriguez-Bigas, H.F. Vasen, E.T. Hawk, J.C. Barrett, A.N. Freedman and S. Srivastava, Revised Bethesda Guidelines for hereditary nonpolyposis colorectal cancer (Lynch syndrome) and microsatellite instability, J Natl Cancer Inst 96(4) (2004), 261-268. 




The Scientific World Journal
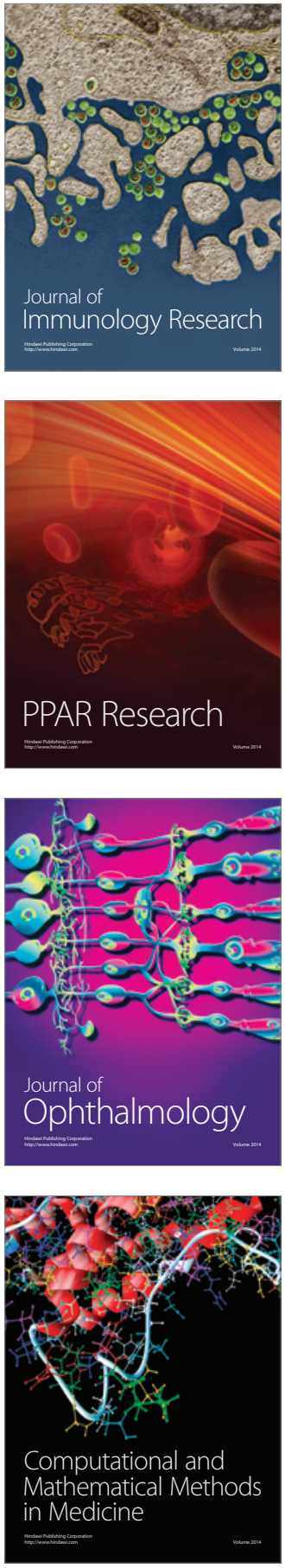

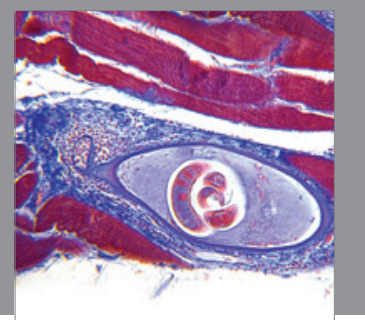

Gastroenterology

Research and Practice
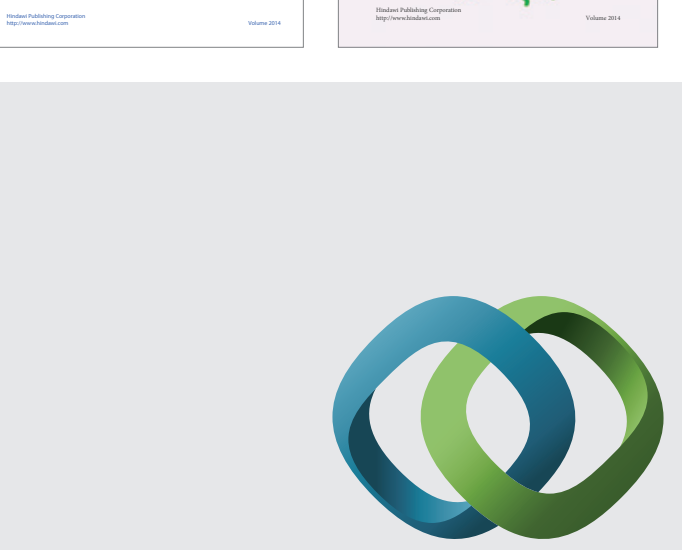

\section{Hindawi}

Submit your manuscripts at

http://www.hindawi.com
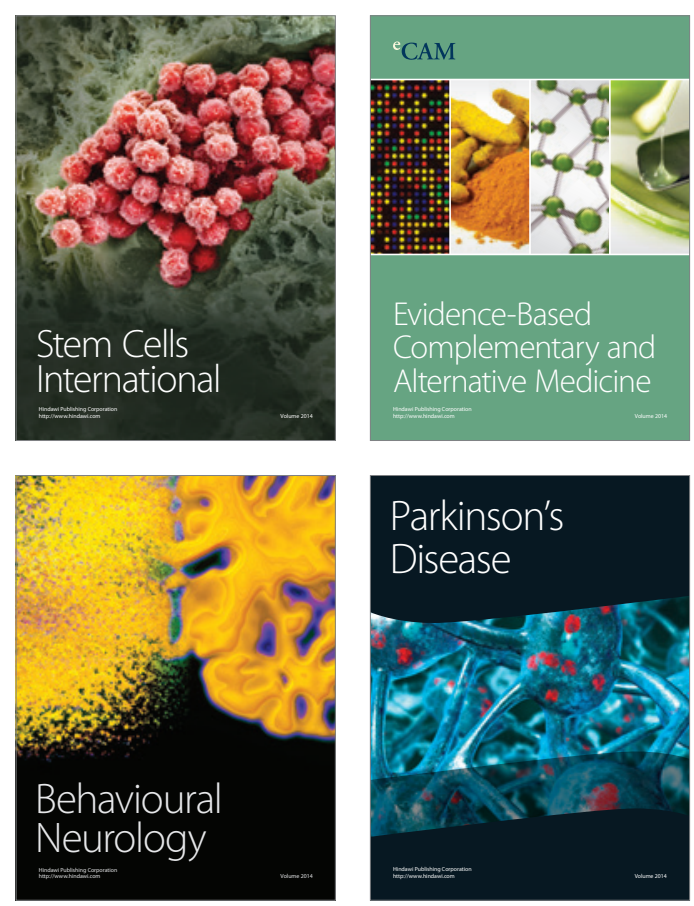

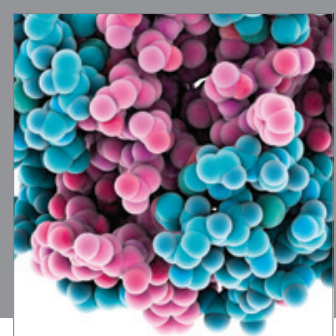

Journal of
Diabetes Research



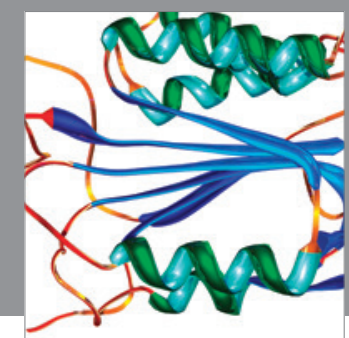

Disease Markers
